\title{
NUMERICAL SERVICE LIFE CALCULATION OF FORMING TOOLS DURING THIXOFORGING USING THE SEHITOGLU MODEL
}

\author{
Bernd-Arno BEHRENS ${ }^{1}$, Kai BRUNOTTE${ }^{1}$, Hendrik WESTER ${ }^{1}$, Alexander ZAITSEV², \\ Maiwand HOOTAK ${ }^{1}$ \\ ${ }^{1}$ Leibniz Universität Hannover, Institute of Forming Technology and Machines, An der Universität 2, \\ 30823 Garbsen, Germany, EU, hootak@ifum.uni-hannover.de \\ ${ }^{2}$ Institute of Metallurgy, Mech. Eng. and Transport, Peter the Great St.-Petersburg Polytechnic Univ., Russia
}

https://doi.org/10.37904/metal.2020.3484

\begin{abstract}
The approach of the most common industry-specific FE-systems for the service life evaluation of forming tools holds some disadvantages. For example, within the decoupled tool analysis, load situations are typically analysed at room temperature and thus, the transient temperature development in the forging die is not considered in the lifetime evaluation. An elastic material behaviour is assumed for the tool component to be analysed. In this way, both deformation and fatigue behaviour are only approximately simulated. However, plastic deformation can occur in critical areas of the tool due to the operationally high tool loads, which can increase during operation and lead to hardening or softening processes in the material. For this reason, neglecting the temperature distribution in the tool makes it impossible to reproduce thermally induced damage processes. Therefore, Sehitoglu's life prediction approach, which is able to take into account thermomechanical loads in the tool during thixoforging and to calculate tool life, is presented in this publication. Since, particularly in thixoforming, where the temperatures exceed those of hot forming, the consideration of thermally induced damage plays a decisive role in order to predict the possibly early failure of the tools. Thus, an appropriate numerical design is possible. For this purpose, experimental tests such as low cycle and thermomechanical fatigue tests were performed for the parameterisation of the model. By means of optimisation routines, the model's parameters were determined. Subsequently, FE-simulations of a cup backward extrusion process were carried out to calculate tool fatigue along with different damage proportions. Finally, validation of the numerical calculations took place by a comparison with experimental results.
\end{abstract}

Keywords: Tool life, fatigue model, thixoforming, FEA, process simulation

\section{INTRODUCTION}

Forging has been known as a suitable process with high process reliability for manufacturing steel components with excellent material properties and high precision for a long time. Nevertheless, manufacturers and engineers must also consider alternative technologies for forging to ensure success and growth of the company through lower production costs and more productive manufacturing [1]. Thixoforming appears to be a promising potential candidate for this solution, forming metals in a partially solidified or partially liquid state, whereby the temperature of the steel components can reach temperatures of over $1400^{\circ} \mathrm{C}$ (semisolid state). As a result, not only the advantages of the two conventional production processes of casting and forging can be exploited, but cost advantages and greater design freedom can also be expected. However, thixoforming of steel still poses major challenges and is not yet established in the industry. It requires fundamental investigations, because the tool is exposed to high thermo-mechanical loads and may fail after only a few cycles. Therefore, the aim of this work is to investigate the possibility of predicting tool life using the example of thixoforging by means of numerical calculations. The overall motivation of this research project is to promote the design and establishment of such innovative manufacturing processes in the future [2]. 


\section{SEHITOGLU MODEL}

The thermo-mechanical fatigue (TMF) life prediction model developed by Sehitoglu et al. [4] is based on the accumulation of the three partial damages fatigue, creep and corrosion damage:

$D^{\text {tot }}=D^{f a t}+D^{o x}+D^{\text {creep }} \Leftrightarrow \frac{1}{N^{\text {tot }}}=\frac{1}{N^{\text {fat }}}+\frac{1}{N^{o x}}+\frac{1}{N^{\text {creep }}}$

$D^{f a t}$ results from a superposition of the Coffin-Manson and Basquin relationship. In $D^{o x}$, the thickness of the oxide layer, which is described by a diffusion approach, and the total strain amplitude are included. $D^{\text {creep }}$ is modelled with a Norton approach [3]. $D^{\text {tot }}$ is the sum of the three damage proportions. Their reciprocals are the corresponding numbers of cycles until failure. Due to the various micro mechanisms affecting the behaviour of materials under thermo-mechanical loading conditions, a profound understanding is required. For this purpose, Sehitoglu et al. [4] developed their model allowing for the calculation of crack formation and early crack growth due to fatigue, environmental and creep damage. Pure fatigue (Figure 1a) is the result of dislocation slips within the material while loaded. Cracking develops due to intrusions and extrusions growing by localised deformation and slip in the plastic zone ahead the crack tip. When the metal surface is exposed to the environment, an oxide layer forms rupturing at a critical thickness. The fresh metal surface underneath the cracked layer is consequently in contact with the environment. The oxide layer grows and ruptures again. Thus, a crack tip intrudes into the material (Figure 1b). Creep damage is due to the formation of void at grain boundaries (Figure 1C). These voids act as preferred point for crack initiation leading to intergranular crack growth [5]. Formula 2-7 show the mathematical description of the Sehitoglu model:

$\frac{\Delta \varepsilon_{m e c h}}{2}=\frac{\sigma_{f}^{\prime}}{E}\left(2 N_{f}^{f a t}\right)^{b}+\varepsilon_{f}^{\prime}\left(2 N_{f}^{f a t}\right)^{c}$

$K_{p}^{e f f}=\frac{1}{t_{c}} \cdot \int_{0}^{t_{c}} D_{o} \cdot \exp \left(\frac{-Q}{R T(t)}\right) d t$

$D^{\text {creep }}=\Phi^{\text {creep }} \cdot \int_{0}^{t_{c}} A \cdot e^{\left(-\frac{\Delta H}{R T}\right)} \cdot\left(\frac{\alpha_{1} \bar{\sigma}+\alpha_{2} \sigma_{H}}{K}\right)^{m} d t$
(2) $\quad D_{o x}=\frac{1}{N_{f}^{o x}}=\left(\frac{h_{c r} \cdot \delta_{0}}{B \cdot \Phi^{o x} \cdot K_{p}^{e f f}}\right)^{\left(-\frac{1}{\beta}\right)} \cdot \frac{2\left(\Delta \varepsilon_{m e c h}\right)^{\left(\frac{2}{\beta}\right)+1}}{\dot{\varepsilon}^{-\left(-\left(\frac{a}{\beta}\right)\right.}}$

(4) $\quad \Phi^{o x}=\frac{1}{t_{c}} \int_{0}^{t_{c}} \exp \left(-\frac{1}{2}\left(\frac{\left(\dot{\varepsilon}_{t h} / \dot{\varepsilon}_{\text {mech }}\right)+1}{\xi^{o x}}\right)^{2}\right) d t$

(6) $\quad \Phi^{\text {creep }}=\frac{1}{t_{c}} \int_{0}^{t_{c}} \exp \left(-\frac{1}{2}\left(\frac{\left(\dot{\varepsilon}_{\text {th }} / \dot{\varepsilon}_{\text {mech }}\right)-1}{\xi \text { creep }}\right)^{2}\right) d t$

where $\sigma_{f}^{\prime}$, E, b, $\varepsilon_{f}^{\prime}, \mathrm{c}, \mathrm{B}, \beta, \mathrm{a}, \delta_{0}, \mathrm{~h}_{\mathrm{cr}}, \mathrm{D}_{\mathrm{o}}, \mathrm{Q}, \mathrm{R}, \xi^{o x}, \mathrm{~A}, \Delta H, \mathrm{~m}, \alpha_{1}, \alpha_{2}, \mathrm{~K}$ (drag stress approximated as linear function containing 2 additional constants) and $\xi^{\text {creep }}$ are parameters and material constants, respectively, needed to be determined. For space reasons, reference is made at this point to [4], where all model equations are observable in detail and no further explanations of each name as well as physical meaning are given in this chapter.
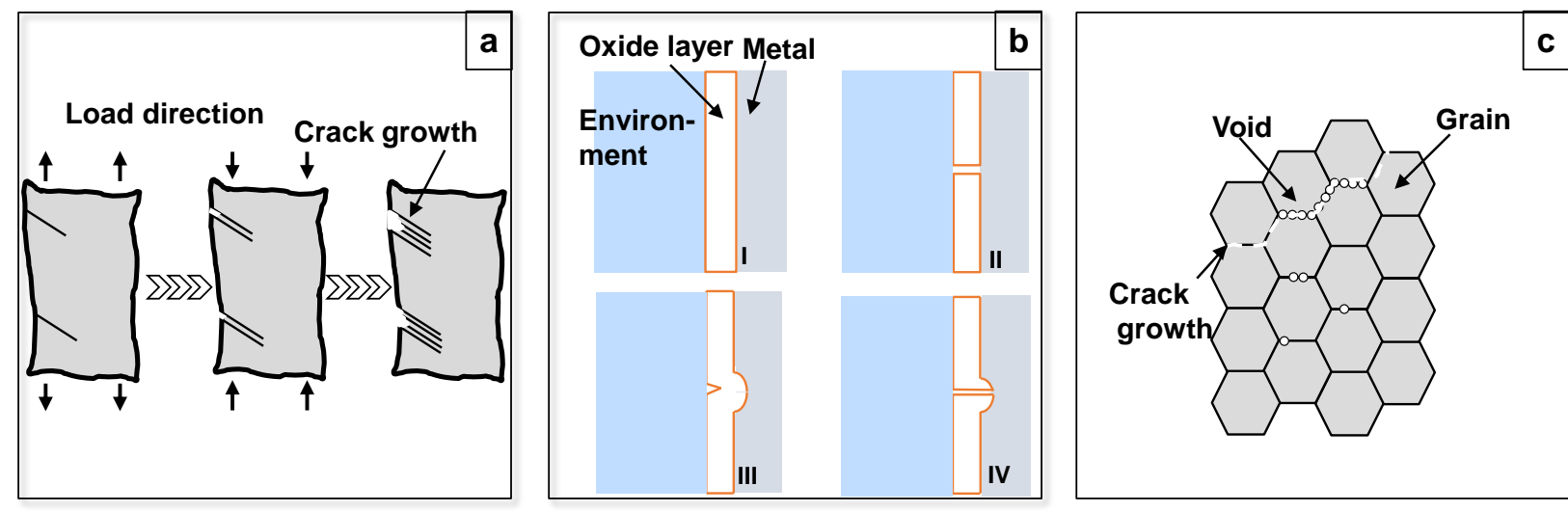

Figure 1 Damage mechanisms: Pure fatigue (a), oxidation damage (b), creep damage (c) [5] 


\section{LOW-CYCLE AND THERMO-MECHANICAL FATIGUE EXPERIMENTS}

To determine the parameters of the Sehitoglu's model, so-called low-cycle fatigue (LCF) and thermomechanical fatigue (TMF) experiments have been performed (72 tests in total). The process window was determined beforehand by means of FE simulations, taking into account different degrees of deformation, strain rates and the temperature loads experienced by the tool. Four strain amplitudes $(0.001-0.003)$, two strain rates $(0.002$ and $0.00051 / \mathrm{s})$ and, for statistical safety, three repetitions were selected as test matrix parameters. As described above, the Sehitoglu approach can be used to determine the total damage consisting of mechanical damage $D^{f a t}$, creep damage $D^{\text {creep }}$ and environmental damage $D^{o x}$. The tests were carried out on the physical forming simulator system Gleeble 3800-GTC at the IFUM to parameterise the model. During the LCF tests, the specimens were cyclically loaded with a constant strain amplitude isothermally in atmospheric air $\left(20^{\circ} \mathrm{C}\right.$; strain ratio $\left.\mathrm{R}=-1\right)$. In addition, so-called in-phase $(\mathrm{IP})$ as well as out-ofphase thermo-mechanical fatigue (OP-TMF) tests were performed, where the amplitude of temperature (oscillating between 300 and $750^{\circ} \mathrm{C}$ ) and strain are in phase or have a shift of $180^{\circ}$, respectively. A notification of crack initiation is possible by the change of the stress amplitude and its sudden drop [4]. In this work, the crack criterion was fulfilled when the value decreased by a minimum of $50 \%$.

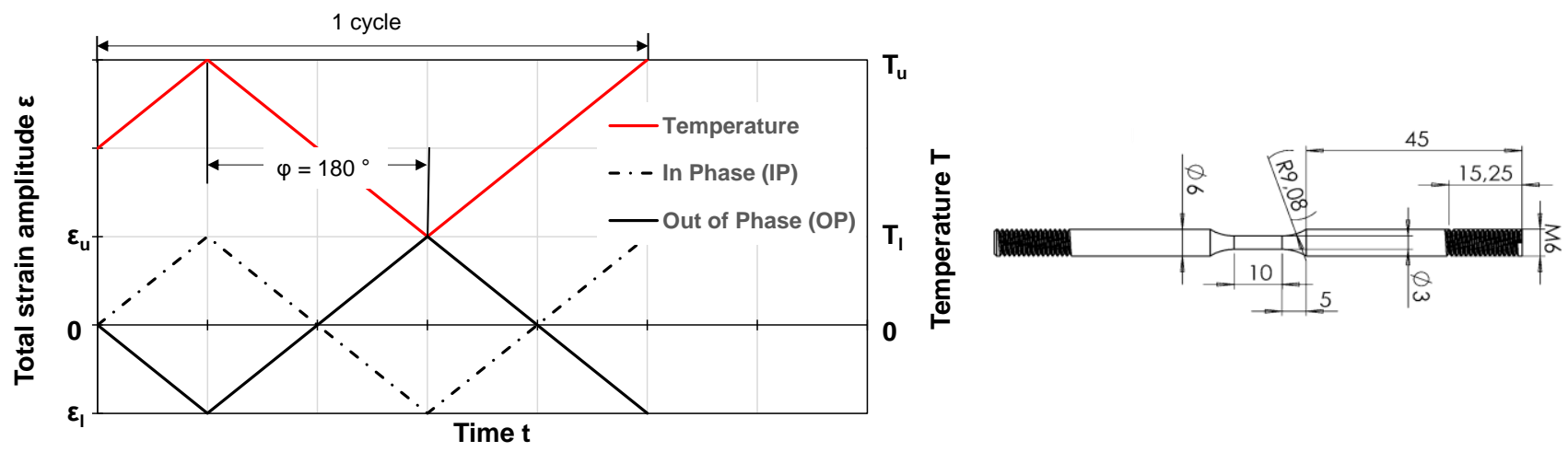

Figure 2 In-phase- and out-of-phase test (left); specimen dimensions (right)

Figures 3-5 show the fracture regions of the specimens after the corresponding different types of thermomechanical cycle fatigue tests. The micrographs were taken by means of grinding longitudinal sections. Therefore, pieces from the failure areas were taken from the specimen by wire erosion which were subsequently etched to make the microstructure visible. When the LCF test is performed at room temperature, the sample is only subjected to mechanical stress. Figure 3 shows that the main mechanism for sample failure is pure fatigue. Due to dislocation movements caused by the load change of tensile and compressive stresses, cracking occurs in the forming zone and the material fails when the critical crack length is reached.

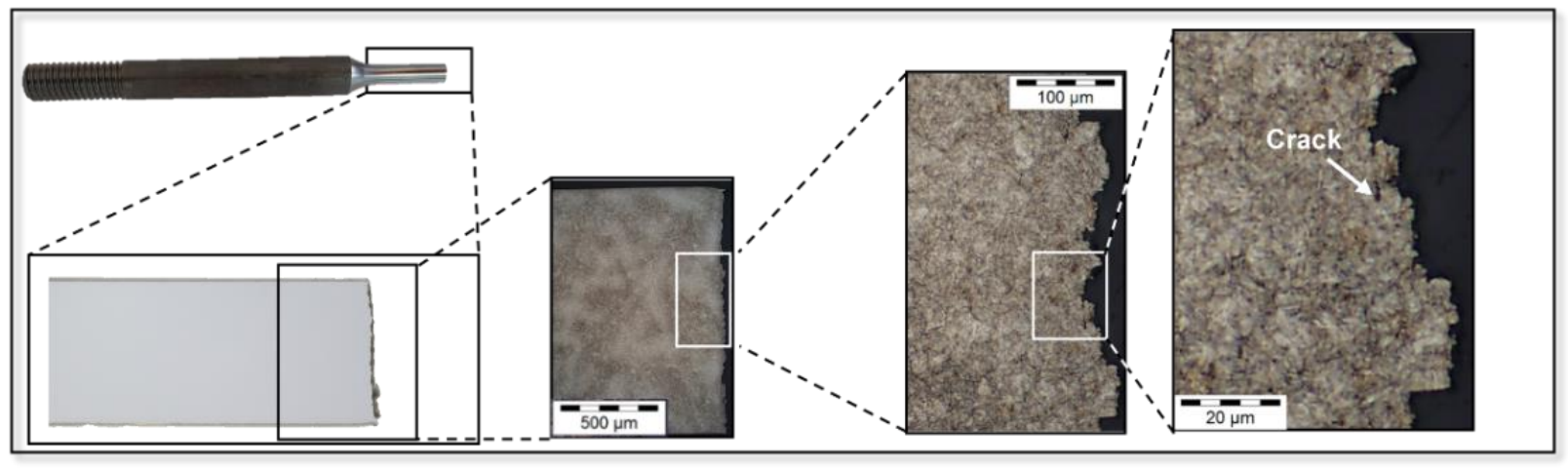

Figure 3 Micrograph of LCF specimen after crack 
For the specimen treated by OP-TMF loads, oxidation occurs in the 1.2367 hot work steel. Scanning electron microscope pictures illustrate the representative surface oxide and oxide "intrusions" (surface-connected cracks filled with oxide) which are transgranular (Figure 4). During the thermo-mechanical loading, the first oxide layers cracks so that the exposed metal surfaces oxidise again. It is typical of OP-cases that an oxidation damage mechanism dominates where the maximum temperature act on the material concurrently to compression stresses since void growth and intergranular cracking mechanisms are suppressed in compression [4].

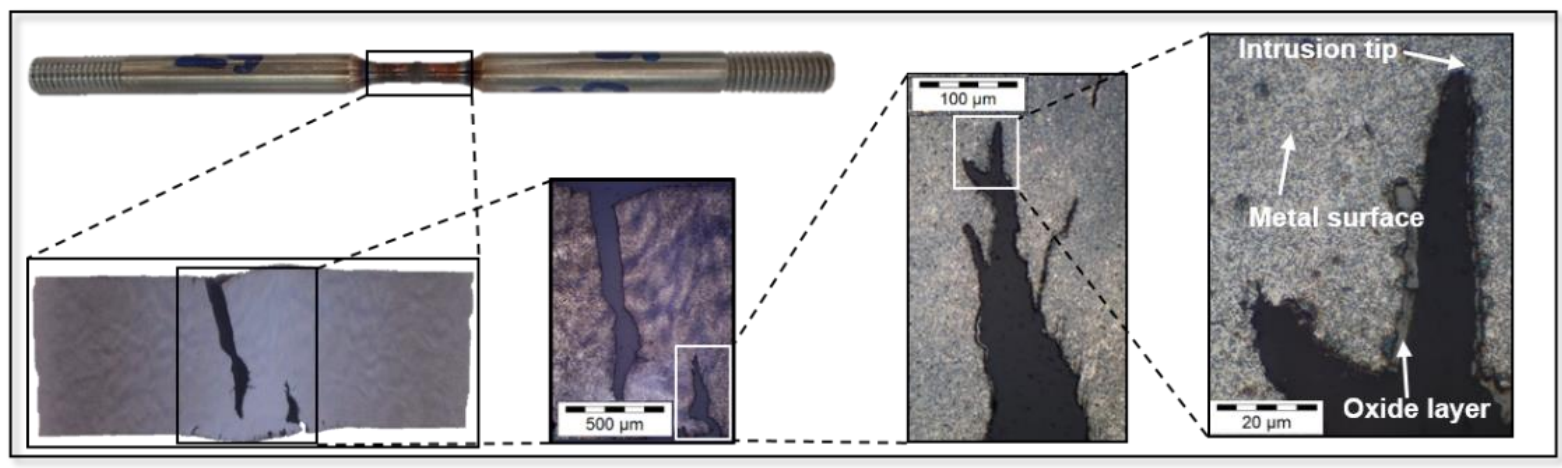

Figure 4 Micrograph of OP-TMF specimen after crack

In contrast, no oxide intrusions formed in the in-phase TMF case. Here, most of the damage occurs in the form of internal intergranular cracking at the grain boundaries. As Figure 5 reveals, micropores are visible at the grain boundaries which lead to the formation of macropores in adjacent areas and eventually crack initiation. The main damage mechanism is creep because tensile stresses coincide with high temperatures promoting void growth. The performance of the above-mentioned LCF- and TMF-tests confirm the findings of the studies in [4]. The main purpose of the experiments in this work has been to determine the parameters of the Sehitoglu model for the tool material under investigation. The results and the procedure for determining the parameters are presented below.

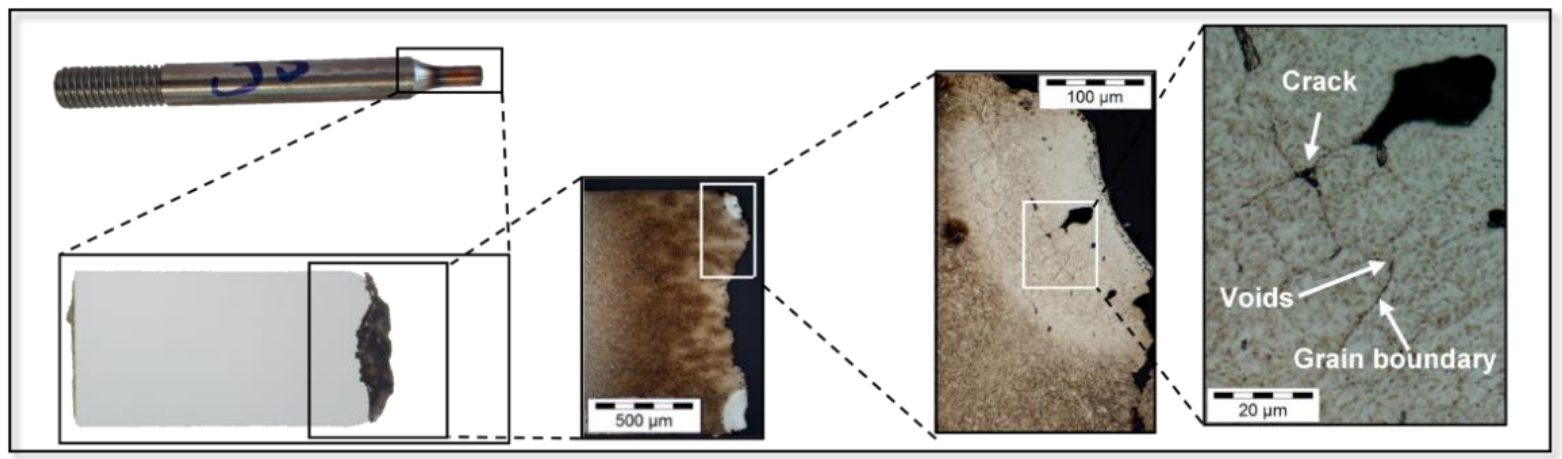

Figure 5 Micrograph of IP-TMF specimen after crack

\section{DETERMINATION OF THE MODEL PARAMETERS}

The LCF tests have shown that the room temperature strain-life curve can be considered as an upper bound on life. In the TMF-tests, the achieved cycles of all test specimens were found to be less than those during room temperature tests. Any decrease in life can be attributed to oxidation effects, creep effects, or both. The "total strain amplitude- cycles until crack" curves are illustrated in Figure 6 for the three cases of isothermal (IT) LCF-tests, thermo-mechanical OP-as well as IP-tests (exemplary at a strain rate of $0.0021 / \mathrm{s}$ ). The number of cycles until crack initiation increases with decreasing strain amplitude. The contribution of oxidation and creep add up to the mechanical damage and thus cause an earlier failure of the material. These mechanisms 
are illustrated by performing the TMF tests, as isothermal tests alone do not capture all damage mechanisms that operate under variable strain-temperature conditions. The results show specimen failure at an earlier point due to the combination of mechanical and thermal loads. Based on the experimental results, the 22 parameters of the model mentioned in chapter 2 could be determined by certain simplifications described below and using the Generalized Reduced Gradient Algorithm (GRG) [6]. Thus, in the case of the isothermal LCF experiment at room temperature, it was assumed that oxidation and creep damage are negligible, which made the determination of the five parameters of the model equations (formula 2) possible. In the OP-TMF test, the proportion of creep damage was neglected and the total damage was calculated from the sum of mechanical plus oxidation damage and compared with the experimental results. This approach allowed to identify the nine parameters of the corresponding model equations (formula 3-5). Finally, the model equations (formula 6 and 7) of creep damage were parameterised. For the description of this model equation, a material law for predicting the stress history in the tool material was also required. This was determined by means of upsetting tests in the relevant temperature range and resulting flow curves approximated by the Hensel-Spittel approach [7].

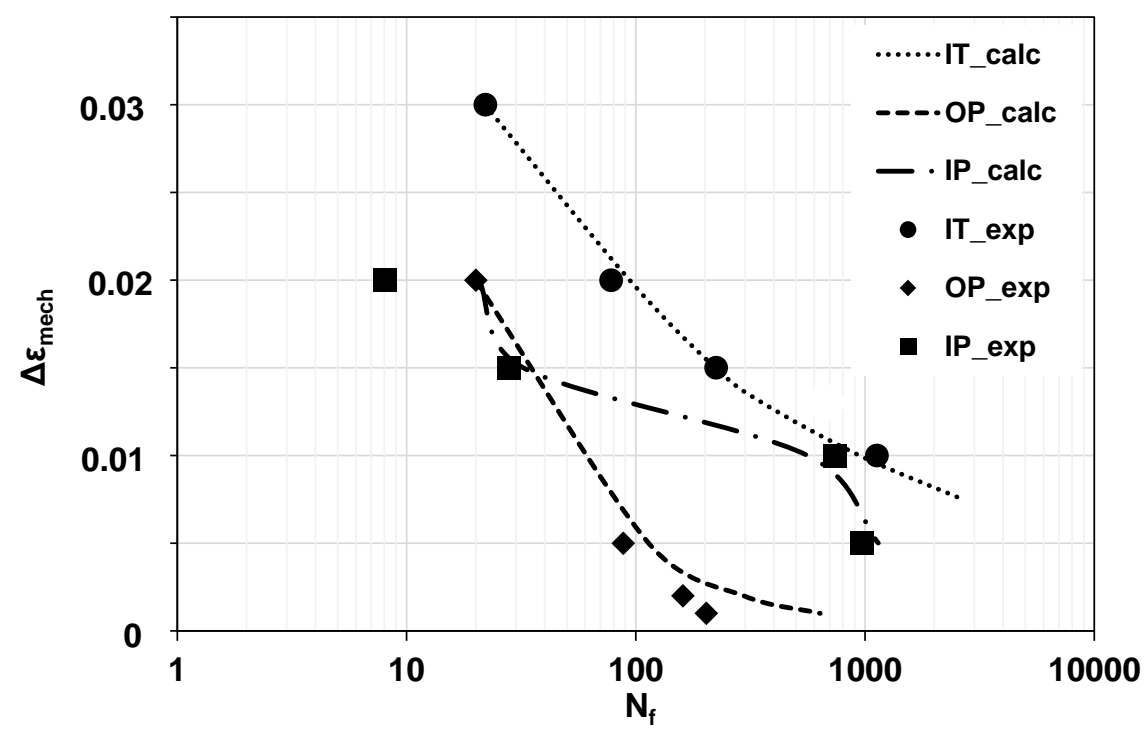

Figure $6 \Delta \varepsilon_{\text {mech }}$ (Total strain amplitude) - $\mathrm{N}_{\mathrm{f}}($ Cycles until crack) - diagram

After determining the model equations, corresponding curves for the different cases of tests were calculated as displayed in Figure 6 . The comparison shows that the calculated curves can predict the cycle number fairly accurately. Subsequently, the total Sehitoglu model has been implemented in Simufact.forming by means of a user subroutine.

\section{NUMERICAL AND EXPERIMENTAL RESULTS OF THIXOFORGING}

As described in previous work [8], a cup backward extrusion process has been investigated. Thereby, the continuous operation, including the transport of the heated billet $(100 \mathrm{Cr} 6)$, setting it into the lower die, forming and post-compaction, was simulated. The results from [8] revealed plastic deformation of the tools after few cycles due to raised temperatures in the tools. Figure 7 shows the simulative and experimental results. By comparing the punch in its initial state with the worn and deformed one after 20 cycles, it is evident that relatively high degrees of deformation of the tool material occur due to the high heat input, accumulating from cycle to cycle. This leads to decreased yield stresses and thus to plastic deformation, which the simulation could have already predicted in advance (Figure 7, right). Due to high thermo-mechanical loads, the implemented fatigue life model predicted that the total number of cycles $\mathrm{N}_{\text {total }}$ was about 15 until failure in the 
mandrel radius area. The experimental results show the condition after 20 cycles and confirm the numerical results by the enhanced damages at same location. This state of damage may be considered as tool failure.
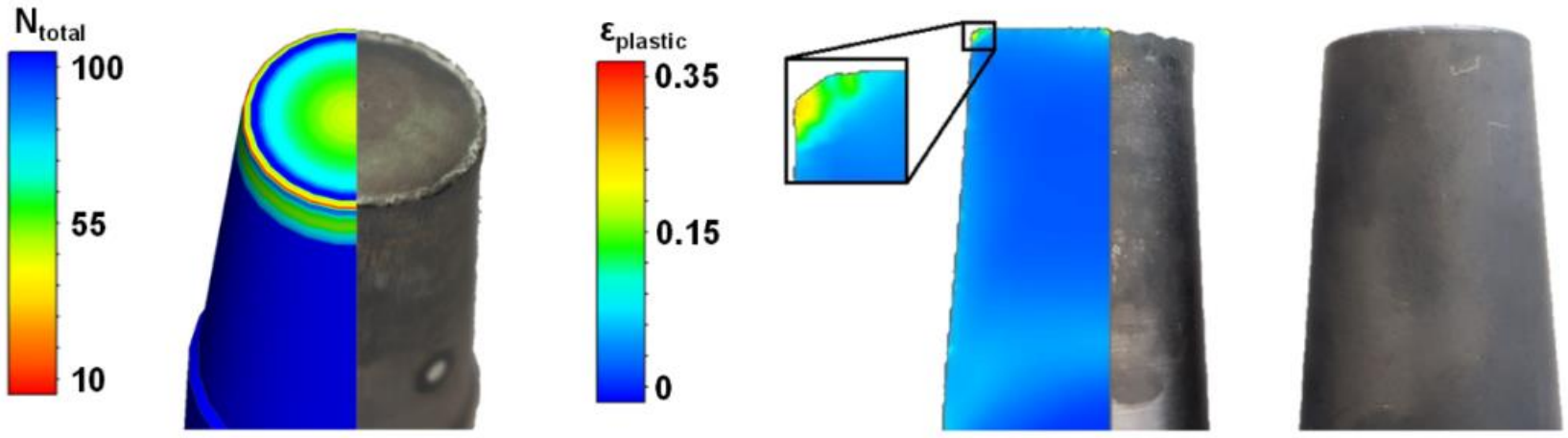

Figure 7 Punch life prediction (left), plastic deformation of the punch (right)

The model allows to calculate the proportions of the occurring damage components of the total damage. Figure 8 shows the numerically determined mechanical, oxidation and creep damage development of the punch. It becomes clear that the proportion of mechanical damage is highest, whereas that of creep damage is negligible. This finding is plausible and compatible to the results of the TMF-tests since in forging the main loads are of OP-type where intergranular damage initiation is suppressed by compression stresses.
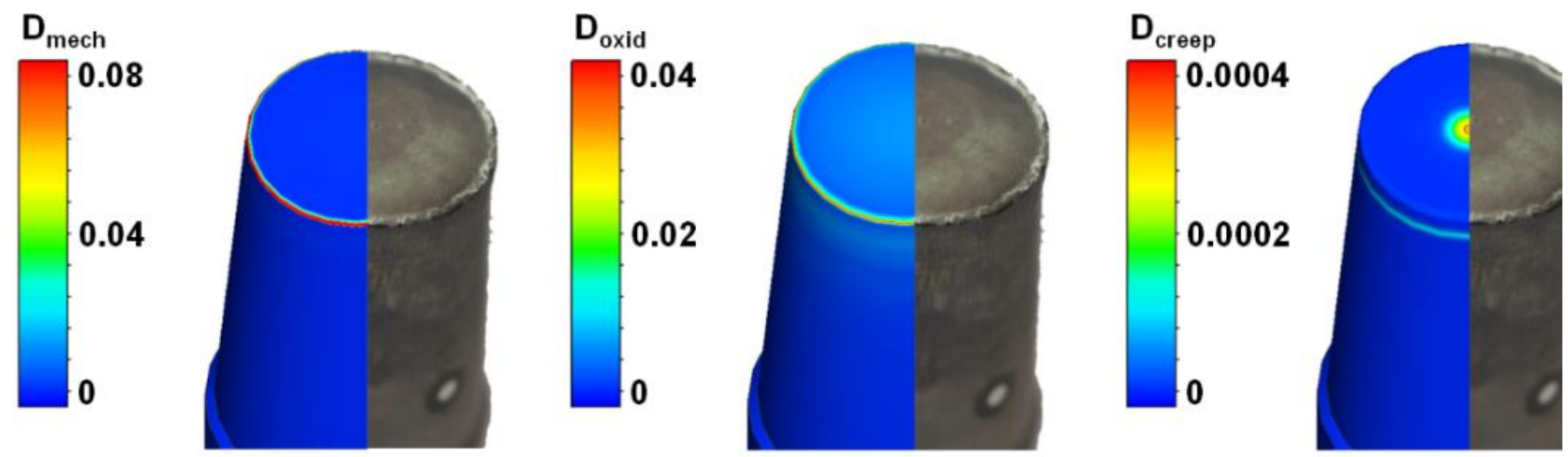

Figure 8 Prediction of damage proportions: Mechanical (left), oxidation (central), creep (right)

\section{CONCLUSION AND OUTLOOK}

In this work, numerical investigations of tool life in thixoforging of steel parts have been presented. For this purpose, at first Sehitoglu's life model was introduced in consideration of the three damage mechanisms. Afterwards, results of the LCF and TMF experiments were shown. Micrographs of the specimens after cracking confirmed the afore mentioned damage mechanisms occuring as main causes for material failure in such tests. Besides, these results made the determination of Sehitoglu's model parameters possible by appyling the GRGAlgorithm. The model equations have been implemented in Simufact.forming by a user subroutine. The comparison of numerical and experimental thixoforging results demonstrate a high correlation. Next steps are microscopic investigations of the punch to characterise the type of damage. Furthermore, the process parameters will be numerically adjusted to increase tool life in this particular case. After optimising the process 
parameters, forging tests will be performed again so that the model will be improved with regard to the further increase of accuracy by the achieved results.

\section{ACKNOWLEDGEMENT}

Sincere thanks to the German Research Foundation (DFG) for financial support (project number 299534929: "Numerical Calculation of Thermal Die Load and Die Life during Thixoforging of Steel").

\section{REFERENCES}

[1] BEHRENS, B. A.; CHUGREEV, A.; HOOTAK, M. (2018): "A sectionwise defined model for the material description of $100 \mathrm{Cr} 6$ in the thixotropic state", AIP Conference Proceedings 1960.

[2] HIRT, G.; SHIMAHARA, H.; SEIDL, I.; KUTHE, F.; ABEL, D.; SCHÖNBOHM, A.: " Semi-Solid Forging of $100 \mathrm{Cr6}$ and X210CrW12 Steel", CIRP Annals, Volume 54, Issue 1, 2005, pp. 257-260.

[3] HALÁSZI, CS., NELHIEBEL, A., GAIER, C., DANNBAUER, H.: „Determination of the material parameters for Sehitoglu's TMF life prediction model", 2007.

[4] SEHITOGLU, H.; NEU, R.: "Thermomechanical Fatigue, Oxidation and Creep": Part I and II. Experiments, Metallurgical Transactions, 20A, 1989, pp. 1755-1783.

[5] MINICHMAYR, R.: „Fatigue Analysis of Aluminium Components using the Damage Rate Model of Neu/Sehitoglu“, TMF-Workshop, Berlin, 2005.

[6] FACO, J.L.D.: A Generalized Reduced Gradient Algorithm for Solving Large-Scale Discrete-Time Nonlinear Optimal Control Problems. IFAC Proceedings Volumes, Volume 22, Issue 2, June 1989, pp. 45-50.

[7] HENSEL, A.; SPITTEL, T.: „Kraft- und Arbeitsbedarf bildsamer Formgebungsverfahren“, Verlag Grundstoffindustrie, 1978.

[8] BEHRENS, B. A.; CHUGREEV, A.; HOOTAK, M. (2019): „Numerical investigations of tool life in thixoforging in consideration of the workpiece in the semi-solid state", Proceedings 28th International Conference on Metallurgy and Materials, Brno, Czech Republic, EU, May 22nd - 24th 2019. 